\title{
The perceived benefit of intraoperative stress modifiers for surgeons: an experimental simulation study in volunteers
}

\author{
Sofia Erestam ${ }^{1 *}$ D, David Bock1, Annette Erichsen Andersson ${ }^{2,3}$, Eva Haglind ${ }^{1}$, Jennifer Park ${ }^{1,4}$ and Eva Angenete ${ }^{1,4}$
}

\begin{abstract}
Background: During surgery, surgeons often work under stressful conditions, which could affect patient safety. Reducing intraoperative stress for surgeons could benefit surgeons and subsequently patients. It is difficult to study stress and stress relief in real life situations due to the multitude of confounding factors. The aim of this study was to evaluate simulated intraoperative stressors on surgeons' stress levels and the effect of an intervention (pause including a sugar-containing drink) during standardized experiments (simulated operations).

Methods: An experimental interventional study was conducted using a simulator. The healthy surgeon volunteers were randomized to intervention and control in a cross-over design. Primary endpoint was salivary cortisol difference between a pause including a sugar containing drink (intervention) and controls. Secondary endpoints were change in heart rate, change in self-perceived stress measured by the State Trait Anxiety Inventory (STAI), and experience of the intraoperative pause. Endpoints were calculated with a mixed effect analysis of covariance (ANCOVA) model.
\end{abstract}

Results: Seventeen surgeons performed 32 experiments. There was no statistically significant difference in salivary cortisol between simulations with and without a pause including a sugar-containing drink; percent reduction, $8 \%$ (0.92 (95\%Cl:0.72;1.18)), $p$-value $=0.469$. The surgeons' self-estimation of intervention was positive, but there was no statistically significant difference in heart rate or STAl.

Conclusions: The surgeons' experience of a pause including a drink was positive but there were no differences in physiological outcomes of the intervention. Lessons learned from this study could contribute to optimizing design of future studies.

Trial registration: Clinicaltrials.gov NCT04626648, Registered November 6, 2020, retrospectively registered.

Keywords: Stress, Surgical simulation, Work break, Saliva cortisol, Patient safety

\footnotetext{
* Correspondence: sofia.erestam@gu.se

'Department of Surgery, Institute of Clinical Sciences, Sahlgrenska Academy

at University of Gothenburg, SSORG - Scandinavian Surgical Outcomes Research Group, Sahlgrenska University Hospital, Gothenburg, Sweden

Full list of author information is available at the end of the article
}

C C The Author(s). 2021 Open Access This article is licensed under a Creative Commons Attribution 4.0 International License, which permits use, sharing, adaptation, distribution and reproduction in any medium or format, as long as you give appropriate credit to the original author(s) and the source, provide a link to the Creative Commons licence, and indicate if changes were made. The images or other third party material in this article are included in the article's Creative Commons licence, unless indicated otherwise in a credit line to the material. If material is not included in the article's Creative Commons licence and your intended use is not permitted by statutory regulation or exceeds the permitted use, you will need to obtain permission directly from the copyright holder. To view a copy of this licence, visit http://creativecommons.org/licenses/by/4.0/. The Creative Commons Public Domain Dedication waiver (http://creativecommons.org/publicdomain/zero/1.0/) applies to the data made available in this article, unless otherwise stated in a credit line to the data. 


\section{Background}

In high-risk environments such as the operating room (OR) the ability to recognise and manage stress in oneself and in others is an important non-technical skill. Stress among professionals in the OR has been linked to decreased patient safety as it has been described to affect surgical performance and intraoperative teamwork negatively [1-6]. Knowledge of factors that influence the level of intraoperative stress among members of the operating team are important.

Professions within the OR team have diverse experiences regarding stressors [2, 5, 7-10]. Surgeons may regularly be exposed to various stressors during surgery such as poor teamwork, distractions/interruptions, patient factors, time pressure/management, technical problems, equipment problems, and personal factors $[5,9$, 10]. The amount of intraoperative stress and surgeons' coping strategies could affect surgical performance [11]. Intraoperative stress may also cause fatigue, which may have negative effects on cognitive performance, motor skills, communication and social skills [6, 12-15]. Among surgeons, stress has sometimes been perceived as a sign of weakness and as something that does not affect "me", but may affect other surgeons $[5,16]$.

Stress is known to increase levels of cortisol, thus reducing these levels may be a measurement of reduced stress. Efforts to reduce stress in order to enhance performance has been made in various settings. In sports, attempts have been made to add sugar in drink or food resulting in improved performance of the sport, reduced cortisol levels and improved self-reported improved energy and ability to focus [17-19]. In academia similar interventions have been shown to improve scholastic achievement for students [20].

Several aspects of intraoperative stress have earlier been assessed in laparoscopic simulators [6, 21, 22]. Studies have also been conducted on different sorts of intraoperative pauses in various settings and the results indicate that intraoperative pauses reduce stress levels, surgical errors and physical discomfort without prolonging the operating time [11, 23-25]. One group has reported reduction in salivary cortisol and fewer intraoperative events when the surgeons were randomized to $5 \mathrm{~min}$ pauses every $30 \mathrm{~min}$ compared with no pauses [23]. An intraoperative pause routine together with a sugar-containing drink was introduced and in a retrospective evaluation we found that the surgical team appreciated the intervention. Surgeons reported that they handled problems in a better way and felt refreshed. Most of the surgeons and scrub nurses reported increased patient safety by an intraoperative paus [25].

\section{Methods}

Based on the hypothesis that intraoperative pauses every other hour including a sugar-containing drink would decrease surgeon's stress levels, the aim of this study was to compare physiologic stress levels measured as cortisol and heart rate, in relation to intraoperative stress and how they was affected by a pause including a sugarcontaining drink during simulated operations.

This experimental interventional study with a twoperiod crossover design was conducted to assess the effects of an intraoperative pause on stress during simulated operations.

\section{Study participants}

Study participants performed the simulated surgery using a two dimensional monitor and instruments similar to clinical surgical laparoscopic equipment (Fig. 1). They were dressed in regular scrubs i.e. scrub cap, surgical gown, gloves and surgical mask, as during regular surgical procedures.

Inclusion criteria for participants were surgical residents or surgeons with maximum 5 years of experience as surgeon (post residency), with employment within Region Västra Götaland. Based on the surgeons' selfassessment the participants were required to have basic laparoscopic skills and to be able to perform an uncomplicated laparoscopic appendectomy independently. All 78 surgeons who met the inclusion criteria were invited to participate in the study (Fig. 2). One of the authors, SE, enrolled all participants by sending emails with study participant information at two different occasions. Exclusion criteria were: diabetes, Addison's disease, medication with steroids or medication that affected heart rate (beta-blockers, calcium antagonists, antiarrhythmics, and digitalis). Smokers were also excluded.

\section{Setting}

Simulated operations took place in a specific room at a University Hospital in Sweden. The room was organized in a similar way to an operating room. The surgical procedures were performed in a laparoscopic simulator, LapSim $^{\oplus}$ with the software TeamSim ${ }^{\circledR}$ provided by (Surgical Science, Gothenburg, Sweden, https:// surgicalscience.com/) [26]. (Fig. 1).

The included study participants operated in the simulator on two different occasions (periods). Each period consisted of four surgical procedures, performed in the same order at both periods (appendectomy, cholecystectomy, retrocecal appendectomy, and cholecystectomy). Stressors were introduced at approximately the same time points during each period, according to a specific manual. Included stressors were bleeding, fog on the camera lens, "black screen", and diathermy without function. Stressors were added manually by the attending researcher (SE) using TeamSim ${ }^{\oplus}$ software.

Each period was divided into two different phases, the pre-intervention phase and the post-intervention phase. 

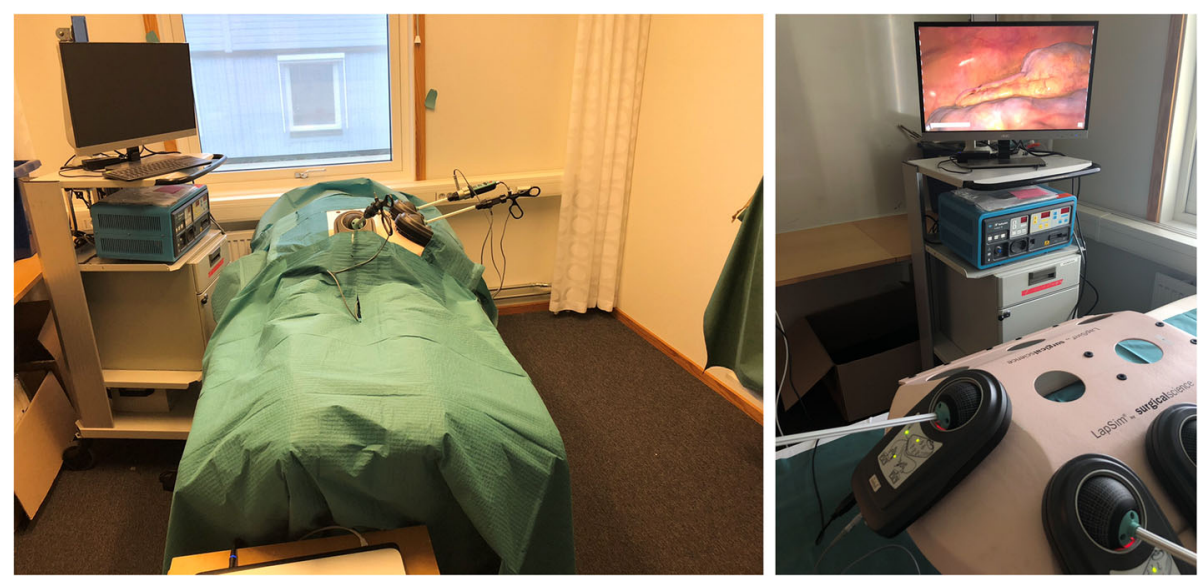

Fig. 1 The simulator set-up

The periods were performed either without an intraoperative pause (control) or with a three-minute long intraoperative pause, including a sugar-containing drink (intervention). The drink was served with a straw by one of the researchers and the study participants kept their surgical gown and gloves on during the pause. (Fig. 2, Fig. 3).

The sequences analyzed were intervention (with pause) and control (no pause).

Study participants were instructed to not eat, drink (other than water) or use tobacco (snuff) $1 \mathrm{~h}$ before each experiment, in order to decrease the risk of affecting their cortisol levels. The diurnal variation in cortisol was taken into account by having the study participants start at the same time point ( $9 \mathrm{am}$ or at $1 \mathrm{pm}$ ) at both simulations.

\section{Randomization}

A computer-generated block-randomization was performed by the statistician (DB). Block-size was unknown to the study participants, who were randomized into one of four sequences (Fig. 2). The majority of the participants were randomized to the sequences: 'pause - no pause' or 'no pause - pause'. Inclusion to the groups 'pause - pause' or to 'no pause - no pause' was done in order to blind the study participants from knowing if their second simulation would be performed with or without pause (Fig. 2). Allocation was concealed by

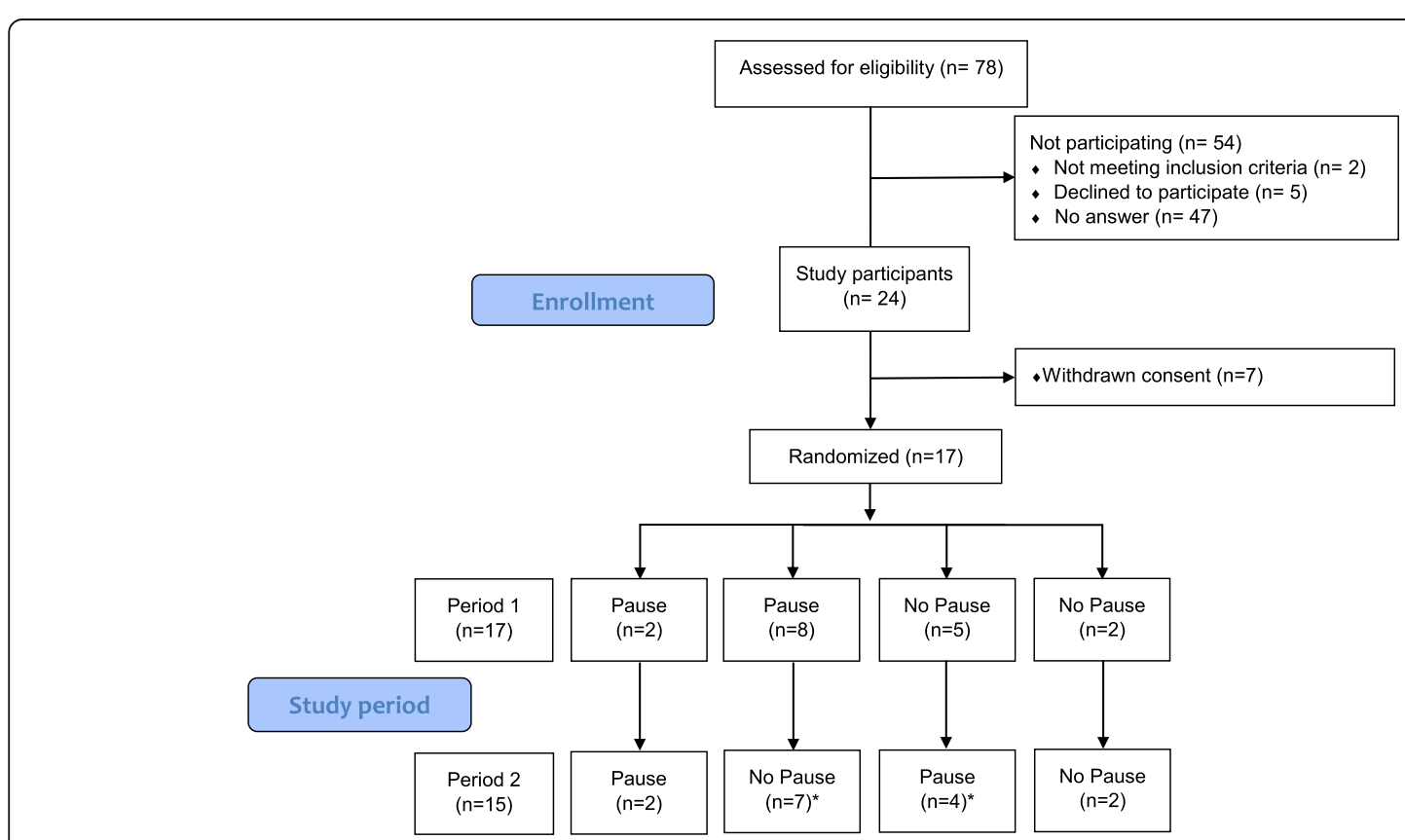

Fig. 2 Flow Chart. *Two surgeons did not participate in the second period due to practical reasons 


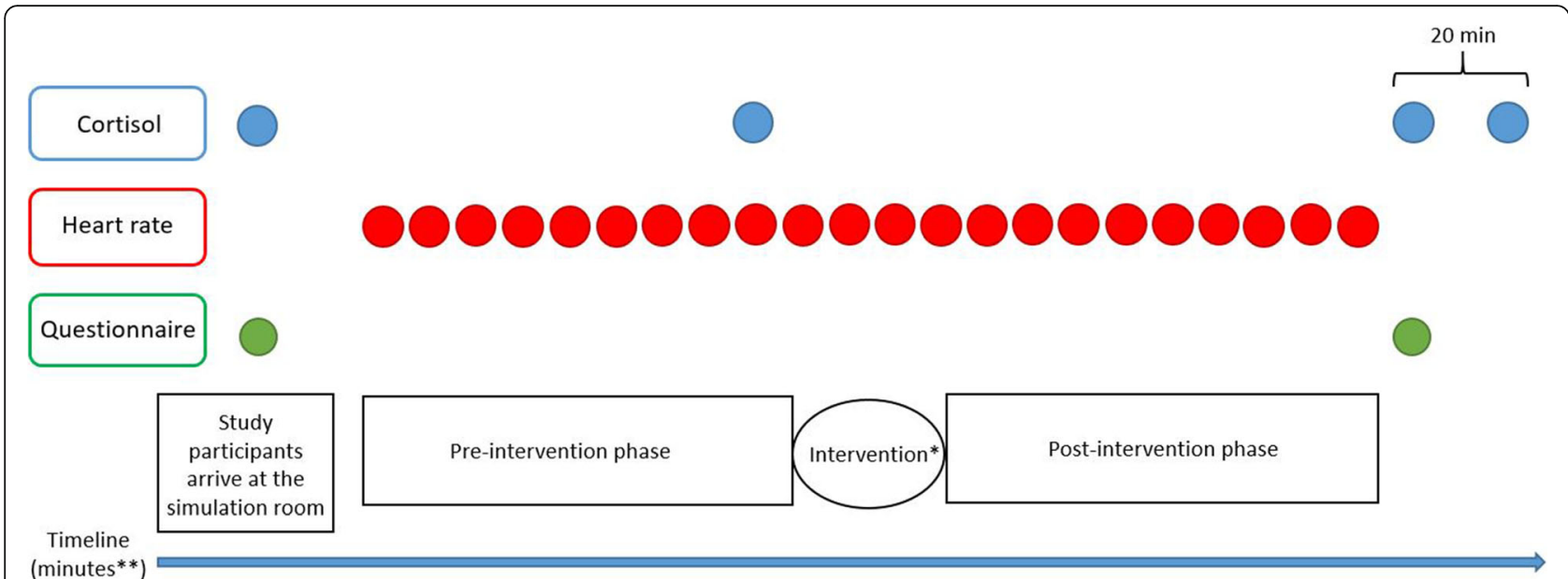

Fig. 3 Timeline for measurements. *Intervention = pause including a sugar-containing drink or control = no pause. ** Total time for simulations differed between 0:40 $\mathrm{h}$ to $2: 02 \mathrm{~h}$

sequentially numbered, opaque, sealed envelopes. Researchers and study participants did not know their randomization until the time for intervention, when the researcher opened the envelope (Fig. 3).

\section{Data collection}

To measure stress salivary cortisol, heart rate and questionnaires were used. Salivary cortisol was collected with a cotton swab, The Salivette ${ }^{\circledR}$ Cortisol (Sarstedt, Nümbrecht, Germany https://www.sarstedt.com/) [27]. A laboratory at the University Hospital analyzed the saliva samples. Salivary cortisol was collected during each period at four different occasions. The first cortisol was collected before the simulation started. The second cortisol was taken between the pre-intervention phase and the post-intervention phase. The third cortisol was taken immediately after the end of the simulation, and the fourth cortisol was taken 20 min after end of simulation. (Fig. 3).

Heart rate (HR) was measured continuously during simulations (Fig. 3). The assessment was made by a pulse-band worn by each study participant (Polar H10 heart rate sensor), data was extracted from https://flow. polar.com/ [28].

Before and after each period participants filled out questionnaires (Fig. 3). Before the first simulation demographic questions, questions on surgical experience, and previous training in the $\mathrm{LapSim}^{\circ}$ were collected. To assess an individual's acknowledgement of how their performance was influenced by stressors the factor "stress recognition" in the Safety Attitude Questionnaire (SAQ) was used [29]. To measure selfperceived stress the State Trait Anxiety Inventory (STAI) was used [30]. The short-version containing six questions has been used frequently in stress assessment among surgeons $[9,21,31-36]$.
During each period, information on time and type for each added stressor was collected in record forms, as was time for salivary cortisol sampling and start/stop times for the simulated operations.

\section{Sample size}

The primary endpoint was change in salivary cortisol (logconcentration) from baseline to average, based on two preintervention and two post-intervention samples (Fig. 3). Assuming a conservative estimate of 0.5 for the correlation, and an intra-individual standard deviation of 0.68 for a single measurement [37]. Then, using the summary statistic approach of Frison and Pocock [38] with 17 evaluable subjects, there would be $80 \%$ power to detect a true reduction of $35 \%$ $[21,31]$ in mean cortisol due to an intraoperative break with a two sided test at $5 \%$ significance level.

\section{Statistical analysis \\ Primary endpoint}

The primary endpoint was change from the baseline salivary cortisol sample in average log-concentration (nanomole (nmol)/ l), based on the two pre-intervention and the two postintervention cortisol samples (Fig. 3). A secondary outcome was maximum of the two post-intervention measurements.

A mixed effect analysis of covariance (ANCOVA) model with treatment (intervention or control), period and sequence as fixed effects, and subject nested within sequence as a random effect, was used. Baseline mean log cortisol from each period was included as a covariate. Least squares means were calculated for each treatment as well as the difference between an intraoperative pause vs. no pause. The estimates were antilogtransferred back to the original scale to obtain the geometric means and the geometric mean ratios and 95\% confidence intervals. 
Table 1 Demographics and questionnaires

\begin{tabular}{|c|c|c|c|c|}
\hline Study participants $n=17$ & Period $1 n=17$ & Missing & Period $2 n=15$ & Missing \\
\hline Age (yrs) median (IQR) & $35(6)$ & & & \\
\hline \multicolumn{5}{|l|}{$\operatorname{Sex}(n)$} \\
\hline Male & 8 & & 6 & 2 \\
\hline Female & 9 & & 9 & \\
\hline \multicolumn{5}{|l|}{ Surgical Experience } \\
\hline Residents & 11 & & & \\
\hline Specialist & 6 & & & \\
\hline BMI median (IQR) & $23(3.1)$ & 1 & & 2 \\
\hline Waist (cm) & $80(13)$ & & & 2 \\
\hline \multicolumn{5}{|l|}{ Previous training in $\operatorname{LapSIM}^{\oplus}(\mathrm{n})$} \\
\hline Yes & 10 & & & \\
\hline No & 7 & & & \\
\hline \multicolumn{5}{|l|}{ Previous experience of playing videogames (n) } \\
\hline Never & 4 & & & \\
\hline More seldom than once a month & 6 & & & \\
\hline At least once a month & 2 & & & \\
\hline At least once a week & 2 & & & \\
\hline Every day & 3 & & & \\
\hline Tobacco 12 h (n) & & & & 2 \\
\hline \multicolumn{5}{|l|}{ Smoked } \\
\hline Snuff & 1 & & 2 & \\
\hline \multicolumn{5}{|l|}{ Nicotine patch/ chewing gum } \\
\hline \multicolumn{5}{|l|}{ Alcohol } \\
\hline Not applicable & 16 & & 13 & \\
\hline \multicolumn{5}{|l|}{ History of smoking (n) } \\
\hline I have never smoked & 14 & & & \\
\hline Previous smoker & 3 & & & \\
\hline \multicolumn{5}{|l|}{ I smoke } \\
\hline \multicolumn{5}{|l|}{ History of using snuff (snus) (n) } \\
\hline I have never used snuff & 11 & & & \\
\hline I have stopped using snuff & 1 & & & \\
\hline I use snuff $<1 x /$ week & 3 & & & \\
\hline I use snuff & 2 & & & \\
\hline \multicolumn{5}{|l|}{ STAI score median (IQR) } \\
\hline Male & $46.67(18)$ & 2 & $38.3(23)$ & 2 \\
\hline Female & $36.7(12)$ & & $33.3(12)$ & \\
\hline SAQ Stress recognition score median (IQR) & $62.5(23.44)$ & & & \\
\hline \multicolumn{5}{|l|}{ Saltin Grimby, physical exercise (n) } \\
\hline Sedentary & 1 & & & \\
\hline Some Physical activity & 6 & & & \\
\hline Regular physical activity & 9 & & & \\
\hline Regular hard physical training & 1 & & & \\
\hline
\end{tabular}


Table 2 Time measurements

\begin{tabular}{|c|c|c|c|c|}
\hline Study participants $n=17$ & Period $1 n=17$ & Missing & Period $2 n=15$ & Missing \\
\hline Time for periods (h) median (IQR) & $1.39(0.33)$ & & 1:06 (0.10) & \\
\hline Time from awakening to first salivary cortisol (h) median (IQR) & $3: 41: 59(4: 30: 30)$ & & 3:02:00 (4:22:59) & 2 \\
\hline Time from pause to cortisol 3 (h) median (IQR) & $0: 42(0: 14)$ & & $0: 32(0: 09)$ & 2 \\
\hline
\end{tabular}

Change from pre-intervention to post intervention phase in heart rate (beats/min), as well as change in STAI score from pre- to post intervention, was analyzed on the log scale with the same statistical model. Questions from earlier studies on stress and surgical performance were used [25, 39]. Subjective measurements by the questionnaire were assessed by Likert scales.

\section{Results}

Out of 78 surgeons (residents or within 5 years of fulfilled residency) seventeen volunteered to participate. They were randomized into one of four different sequences and performed in total 32 simulations. Two of the surgeons did not participate in the second period due to practical reasons (Fig. 2, Table 1). The inclusion was open from June to October 2019 and the study was performed between September and December 2019.

Total time for simulations differed between $0: 40 \mathrm{~h}$ to 2:02 $\mathrm{h}$. There was a time difference between the first median (IQR) 1:39 $\mathrm{h}(0.33)$ and second simulation median (IQR) 1:06 h (0.10) (Table 2). Time from awakening to first salivary cortisol differed between 0:28 $\mathrm{h}$ to $9: 02 \mathrm{~h}$. The intervention (the tree minute pause) took place between the pre-intervention phase and the postintervention phase, which occurred between $0: 22 \mathrm{~h}$ and 1:26 h after simulation start. Time from intervention to end of simulation and the third salivary cortisol sample differed between 0:19 $\mathrm{h}$ and 1:02 $\mathrm{h}$ (Table 2).

A total of 122 samples of salivary cortisol from 17 participants were analyzed. Results from five of the initial samples were missing due to insufficient amount of saliva, and one sample was lost (Table 3). Salivary cortisol at the pre-intervention phase was median (interquartile

Table 3 Primary and secondary outcome

\begin{tabular}{llll}
\hline Median (IQR) & Pause & No Pause & Total \\
\hline Salivary Cortisol (nmol/l) & & & \\
Pre-intervention phase & $5.1(3.40)$ & $4.8(4.65)$ & $4.9(3.50)$ \\
Post-intervention phase & $4.6(2.10)$ & $4.3(2.39)$ & $4.5(2.35)$ \\
Heart Rate (beats/min) & & & \\
Pre-intervention phase & $91.5(21)$ & $89.5(30)$ & $93.0(25)$ \\
Post-intervention phase & $90.8(18)$ & $91.8(29)$ & $91.8(20)$ \\
STAl score & & & \\
Pre-intervention phase & $33.3(10.83)$ & $35.0(10.00)$ & $33.3(10.00)$ \\
Post-intervention phase & $41.7(24.17)$ & $38.3(26.67)$ & $40(16.67)$ \\
\hline
\end{tabular}

range (IQR)) 4.9 (3.5) nmol/l. During the postintervention phase, after an intraoperative pause, salivary cortisol was median (IQR) $4.6(2.10) \mathrm{nmol} / \mathrm{l}$ and in the control group median (IQR) 4.3 (2.39) nmol/l (Table 3). There was no statistically significant difference in the primary endpoint salivary cortisol between the intervention and the control group, mean ratio 0.92 (95\%CI:0.72; 1.18) (Table 4, Fig. 4). Analysis of maximum cortisol was calculated but did not differ from mean cortisol.

The surgeons' self-perceived assessment of taking an intra-operative pause including a sugar-containing drink was positive. Nine of 16 surgeons experienced that the pause hade made them handle problems in a better way, five did not know, and 14 of 16 surgeons reported feeling more alert after intervention (Table 5).

Thirty-one measures of heart rate were analyzed, one measurement was lost due to technical failure. There was no statistically significant differences in heart rate between simulations with intervention compared with controls 0.97 (95\%CI:0.94;1.00) (Table 3, Table 4, Fig. 4).

Changes in STAI-score was calculated for thirty simulated operations, two STAI-score was not filled out. STAI-score compared between simulations with interventions and controls did not differ 0.99 (95\%CI:0.89; 1.09) (Table 3, Table 4, Fig. 4).

\section{Discussion}

In this study, we did not find that an intraoperative pause resulted in a reduction in stress amongst surgeons using physiological measures such as salivary cortisol

Table 4 Percental change from pre-intervention, primary and secondary outcome

\begin{tabular}{llll}
\hline & $\begin{array}{l}\text { Percent change } \\
\mathbf{9 5 \% ~ C l}\end{array}$ & Yes vs. No & p-value \\
\hline Salivary Cortisol & & & \\
Pause: Yes & $-21.6 \%(-35.5--4.7)$ & $0.92(95 \% \mathrm{Cl}: 0.72 ; 1.18)$ & 0.4694 \\
Pause: No & $-14.7 \%(-29.8-3.5)$ & & \\
Heart Rate & & & \\
Pause: Yes & $0.4 \%(-3.7-3.0)$ & $0.97(95 \% \mathrm{Cl}: 0.94 ; 1.00)$ & 0.0650 \\
Pause: No & $2.6 \%(-0.83-6.1)$ & & \\
STAl & & & \\
Pause: Yes & $7.9 \%(-0.56-17.1)$ & $0.99(95 \% \mathrm{Cl}: 0.89 ; 1.09)$ & 0.7561 \\
Pause: No & $8.6 \%(0.1-18.0)$ & & \\
\hline
\end{tabular}



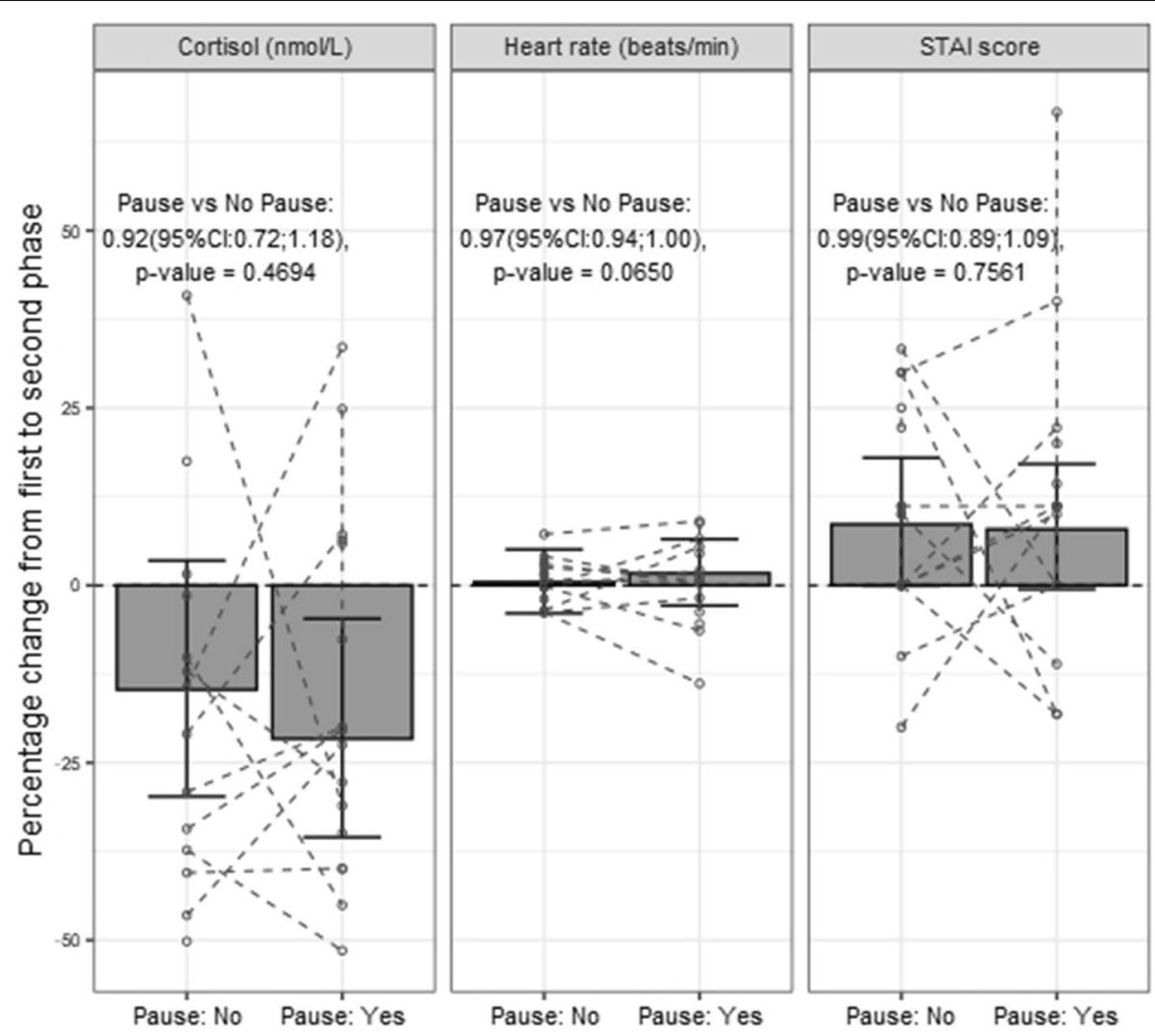

Fig. 4 Change in Cortisol, heart rate and STAI score from pre-intervention phase to post-intervention phase

and, heart rate or a self-assessing questionnaire (STAI). However, a majority of the participating residents and surgeons reported that they felt more alert and that a pause improved their problem-solving skills.

Our hypothesis was that an intraoperative pause would decrease surgeons' objective and subjective stress levels. Salivary Cortisol, HR and STAI have been validated, where the different assessments correlates and can be used to capture responses to stress during surgery [21, 31]. Although we did not find any association between the intraoperative pause and salivary cortisol, heart rate or STAI, previous studies on stress in combination with intraoperative pauses have reported associations between self-assessed stress, salivary cortisol, heart rate and intraoperative pauses [23, 24]. Engelmann, Schneider [23] and Hallbeck, Lowndes [24] all used several micro breaks as their intervention, whereas the intervention we studied was one intraoperative pause lasting $3 \mathrm{~min}$, including a sugar-containing drink.

The effect of sugar on stress and performance has to our knowledge not been studied in a surgical environment before. In sports, athletes who ingested sugarcontaining drinks instead of water during competitions increased their performance in combination with a reduction in cortisol [17]. We expected sugar to have a positive effect on surgeons' stress levels, but it may have affected our salivary cortisol samples negatively. Cortisol is released into the circulation by activation of the Hypothalamus-Pituitary-Adrenal (HPA) axis and peaks usually 20-30 min after the introduction of stress [40]. The initial study design was a two-hour operation with the pause after $1 \mathrm{~h}$ of surgery. The reality was that the simulation time differed between $0: 40 \mathrm{~h}$ to $2: 02 \mathrm{~h}$, as some surgeons were faster than others. This could have

Table 5 Surgeons' self-perceived assessment of taking a pause Has the pause made you handle problems in a better way? (n) 
had impact on the cortisol as the third cortisol sample was collected $0: 19 \mathrm{~h}$ to $1: 02 \mathrm{~h}$ after a pause with a sugarcontaining drink.

Time from awakening to first salivary cortisol (Table 1) had a substantial variation $(0: 28 \mathrm{~h}-9: 02 \mathrm{~h})$. This could also have affected the results as salivary cortisol normally peaks about 30-45 min after awakening and declines throughout the day [41]. In a supporting analysis cortisol diurnal curve was taken into account by adding simulation time ( $9 \mathrm{am}$ or $1 \mathrm{pm})$ as a factor in the statistical model, however this did not change the result.

It is also possible that our design was insufficiently stressful for the study-participants included in this study. The LapSim ${ }^{\circ}$ simulator is primarily constructed as a teaching tool for residents to shorten their laparoscopic learning curve $[42,43]$. Although not all participating surgeons had used the LapSim ${ }^{\circ}$ previously, it is possible that they had too much surgical experience to perceive the simulations as stressful. In this study, we included residents and surgeons with a maximum of 5 years of surgical experience since we aimed to include study participants who were similar in their laparoscopic experience and thereby reducing inter-individual variability. Including more experienced surgeons would have increased the "possible to include" group but we refrained from this to decrease possible variability in stress responses. More experienced surgeons probably will have developed coping strategies against intraoperative stressful events to a larger extent than less experienced ones even if this is not universal $[10,44]$.

The sample size calculation showed that we needed to include 17 study participants to have the power to detect a true reduction of $35 \%$ in salivary cortisol, based on cortisol decrease in two previous studies [21, 31]. Although we included 17 residents and surgeons, we did not have comparable data for all of them, and our study only demonstrated an $8 \%$ reduction in salivary cortisol. A longer accrual period and more participants would have been preferable. In order to definitely describe a cause-effect relationship between stress, cortisol and anti-stress effect of a pause and drink intervention it would be of interest to perform a study with lessons learned as the subjective measures indicate that a pause is beneficial. The results concerning surgeon experience of a pause and drink are similar to our previous retrospective study, where $75 \%$ of the surgeons reported that they handled problems in a better way after a pause, and 93\% felt more alert after a pause [25]. Effects experienced by those participating in experiments, studies or treatments should always be respected.

Another reason for future studies on the subject intraoperative stress is the fact that surgeons have reported that stress often is seen as a sign of weakness within the surgical community $[5,16]$. At the same time many surgeons indicate that stress does not affect their personal surgical performance $[5,16]$. To assess our study participants' individual understanding of the impact of working in a stressful environment, the SAQ stress recognition domain was included in the baseline questionnaire. Stress recognition has been defined as "the extent to which individuals acknowledge personal vulnerability to stressors such as fatigue, personal problems, and emergency situations" [29, 45].

Strengths of this study include the experimental setting, with standardized "operations", standardized stressors and a randomized design where each participant was blinded for each experiment (intervention or control). The experiment leader was also blinded up to the moment for the intervention (or not). In connection with this a limitation was that times to complete the standardized operations differed which could have influenced tiredness, possibly a stressor. One limitation was that the sample size was insufficient. Some of the surgeons did not participate in the second period, and some of the cortisol samples could not be analyzed. Another possible weakness in this study was the abovementioned possibility that the experimental set-up was insufficiently stressful. Also, although the effort was to make the simulations as genuine as possible, there were several disparities from operations in an OR. In real life the surgeon has the entire operating team to rely on, in this study the surgeon was alone and had to solve every problem by him/herself - an added stressor compared to real life. In an effort to simulate real life in an operating room the participants were encouraged to talk to the experimental leader as if she was acting as scrub nurses. One of the main issues during simulations was that the simulator at several occasions stopped working, which led to restarting of the computer. Whether this acted as a stressor for the participants or only for the leader of the experiment is unclear.

\section{Conclusions}

In this study an intraoperative pause including a sugarcontaining drink during simulated operations did not significantly change physiological responses to surgeon stress levels. However, the intervention was appreciated by surgeons who felt that their problem-solving abilities were improved. The lessons learned from this study could be of benefit for a future study with even more realistic stressors, one starting time for all and a larger study population.

\section{Abbrevations}

CRF: Clinical record form; Cl: Confidence interval; HR: Heart rate; HPA: Hypothalamus-pituitary-adrenal; IQR: Interquartile range; I: Litre; nmol: Nanomole; OR: Operating room; SAQ: Safety attitude questionnaire; STAl: State trait anxiety inventory

Acknowledgements Not applicable. 


\section{Authors' contributions}

All authors contributed to the design and the preformed analysis plan. DB and SE performed the analysis, SE wrote the initial manuscript. All authors contributed in editing and revising the manuscript, and all have approved of the final manuscript

\section{Funding}

The study was financed by grants from the Swedish state under the agreement between the Swedish government and the county councils, the ALF agreement (ALFGBG-716581 and ALFBGB-4307771). Support was received from Bror and Anna-Lisa Björnsson foundation. The funding sources have no influence on the result of this study. Open Access funding provided by University of Gothenburg.

\section{Availability of data and materials}

Not applicable due to the small sample size hence the possibility for persons familiar with the study to identify the study participants.

\section{Declarations}

\section{Ethics approval and consent to participate}

Ethical approval was obtained from the Swedish Ethical Review Authority of the Swedish state (ministry of education and research) with the Dnr: 201902316

\section{Consent for publication}

Study participants were informed about the study on several occasions, by email and/ or at meetings. Written informed consent was obtained from all participants before entering the study.

\section{Competing interests}

The authors have no competing interests.

\section{Author details}

'Department of Surgery, Institute of Clinical Sciences, Sahlgrenska Academy at University of Gothenburg, SSORG - Scandinavian Surgical Outcomes Research Group, Sahlgrenska University Hospital, Gothenburg, Sweden. ${ }^{2}$ Institute of Health and Care Science, University of Gothenburg, Gothenburg, Sweden. ${ }^{3}$ Department of Orthopedics, Sahlgrenska University Hospital, Gothenburg, Sweden. ${ }^{4}$ Department of Surgery, Region Västra Götaland, Sahlgrenska University Hospital, Gothenburg, Sweden.

Received: 26 February 2021 Accepted: 22 April 2021

\section{Published online: 29 May 2021}

\section{References}

1. Arora S, Sevdalis N, Nestel D, Woloshynowych M, Darzi A, Kneebone R. The impact of stress on surgical performance: a systematic review of the literature. Surgery. 2010;147:318-30 330 e311-316.

2. Wheelock A, Suliman A, Wharton R, Babu ED, Hull L, Vincent C, et al. The impact of operating room distractions on stress, workload, and teamwork. Ann Surg. 2015;261(6):1079-84. https://doi.org/10.1097/SLA.0000000000001 051.

3. Anton NE, Montero PN, Howley LD, Brown C, Stefanidis D. What stress coping strategies are surgeons relying upon during surgery? Am J Surg. 2015;210(5):846-51. https://doi.org/10.1016/j.amjsurg.2015.04. 002.

4. Driskell JE, Salas E, Johnston J. Does stress lead to a loss of team perspective? Group Dyn Theory Res Pract. 1999;3(4):291-302. https://doi. org/10.1037/1089-2699.3.4.291.

5. Arora S, Sevdalis N, Nestel D, Tierney T, Woloshynowych M, Kneebone R. Managing intraoperative stress: what do surgeons want from a crisis training program? Am J Surg. 2009;197(4):537-43. https://doi.org/10.1016/j.a mjsurg.2008.02.009.

6. Hassan I, Weyers P, Maschuw K, Dick B, Gerdes B, Rothmund M, et al. Negative stress-coping strategies among novices in surgery correlate with poor virtual laparoscopic performance. Br J Surg. 2006;93(12):1554-9. https://doi.org/10.1002/bjs.5544.

7. Sonoda Y, Onozuka D, Hagihara A. Factors related to teamwork performance and stress of operating room nurses. J Nurs Manag. 2018;26(1): 66-73. https://doi.org/10.1111/jonm.12522.
8. Gurman GM, Klein M, Weksler N. Professional stress in anesthesiology: a review. J Clin Monit Comput. 2012;26(4):329-35. https://doi.org/10.1007/s 0877-011-9328-7.

9. Arora S, Hull L, Sevdalis N, Tierney T, Nestel D, Woloshynowych M, et al. Factors compromising safety in surgery: stressful events in the operating room. Am J Surg. 2010;199(1):60-5. https://doi.org/10.1016/j.amjsurg.2009.07.036.

10. Wetzel CM, Kneebone RL, Woloshynowych M, Nestel D, Moorthy K, Kidd J, et al. The effects of stress on surgical performance. Am J Surg. 2006;191(1): 5-10. https://doi.org/10.1016/j.amjsurg.2005.08.034.

11. Wetzel CM, Black SA, Hanna GB, Athanasiou T, Kneebone RL, Nestel D, et al. The effects of stress and coping on surgical performance during simulations. Ann Surg. 2010;251(1):171-6. https://doi.org/10.1097/SLA.0b013e3181b3b2be.

12. Dawson D, Reid K. Fatigue, alcohol and performance impairment. Nature. 1997;388(6639):235. https://doi.org/10.1038/40775.

13. Krueger GP. Sustained work, fatigue, sleep loss and performance: a review of the issues. Work Stress. 1989;3(2):129-41. https://doi.org/10.1080/026783 78908256939 .

14. Whitmore J, Fisher S. Speech during sustained operations. Speech Comm. 1996;20(1-2):55-70. https://doi.org/10.1016/S0167-6393(96)00044-1.

15. Pilcher $\mathrm{J}$, Huffcutt Al. Effects of sleep deprivation on performance: a metaanalysis. Sleep. 1996;19(4):318-26. https://doi.org/10.1093/sleep/19.4.318.

16. Sexton JB, Thomas EJ, Helmreich RL. Error, stress, and teamwork in medicine and aviation: cross sectional surveys. BMJ Br Med J. 2000;320(7237):745-9. https://doi.org/10.1136/bmj.320.7237.745.

17. Nieman DC, Gillitt ND, Sha W, Meaney MP, John C, Pappan KL, et al. Metabolomics-based analysis of Banana and pear ingestion on exercise performance and recovery. J Proteome Res. 2015;14(12):5367-77. https://doi. org/10.1021/acs.jproteome.5b00909.

18. Rowlands DS, Houltham S, Musa-Veloso K, Brown F, Paulionis L, Bailey D. Fructose-glucose composite carbohydrates and endurance performance: critical review and future perspectives. Sports Med. 2015;45:1561-76.

19. Vandenbogaerde TJ, Hopkins WG. Effects of acute carbohydrate supplementation on endurance performance: a meta-analysis. Sports Med. 2011;41:773-92.

20. Lindahl $M$, Theorell $T$, Lindblad F. Test performance and self-esteem in relation to experienced stress in Swedish sixth and ninth graders-saliva cortisol levels and psychological reactions to demands. 2005;94:489-95.

21. Arora S, Sevdalis N, Aggarwal R, Sirimanna P, Darzi A, Kneebone R. Stress impairs psychomotor performance in novice laparoscopic surgeons. Surg Endosc. 2010;24(10):2588-93. https://doi.org/10.1007/s00464-010-1013-2.

22. Arora S, Aggarwal R, Moran A, Sirimanna P, Crochet P, Darzi A, Kneebone R, Sevdalis N Mental practice: effective stress management training for novice surgeons. J Am Coll Surg 212:225-233. https://doi.org/10.1016/j.ja mcollsurg.2010.09.025.

23. Engelmann C, Schneider M, Kirschbaum C, Grote G, Dingemann J, Schoof S, et al. Effects of intraoperative breaks on mental and somatic operator fatigue: a randomized clinical trial. Surg Endosc. 2011;25(4):1245-50. https:// doi.org/10.1007/s00464-010-1350-1.

24. Hallbeck MS, Lowndes BR, Bingener J, Abdelrahman AM, Yu D, Bartley A, et al. The impact of intraoperative microbreaks with exercises on surgeons: a multi-center cohort study. Appl Ergon. 2017;60:334-41. https://doi.org/10.1 016/j.apergo.2016.12.006.

25. Erestam $\mathrm{S}$, Angenete $\mathrm{E}$, Derwinger $\mathrm{K}$. The surgical Teams' perception of the effects of a routine intraoperative pause. World J Surg. 2016;40(12):2875-80. https://doi.org/10.1007/s00268-016-3632-9.

26. Surgical Science Surgical Science. https://surgicalscience.com/.

27. Sarstedt Sarstedt. https://www.sarstedt.com/.

28. Polar Polar Flow. https://flow.polar.com/.

29. Sexton JB, Helmreich RL, Neilands TB, Rowan K, Vella K, Boyden J, et al. The safety attitudes questionnaire: psychometric properties, benchmarking data, and emerging research. BMC Health Serv Res. 2006;6(1):44. https://doi.org/1 0.1186/1472-6963-6-44.

30. Spielberger CD, Gorsuch RL, Lushene RE. The state-trait anxiety inventory: Testmanual. Palo Alto, CA: Consulting Psychologist Press; 1970.

31. Arora S, Tierney T, Sevdalis N, Aggarwal R, Nestel D, Woloshynowych M, et al. The Imperial stress assessment tool (ISAT): a feasible, reliable and valid approach to measuring stress in the operating room. World J Surg. 2010;34(8):1756-63. https://doi.org/10.1007/s00268-010-0559-4.

32. Hull L, Arora S, Kassab E, Kneebone R, Sevdalis N. Assessment of stress and teamwork in the operating room: an exploratory study. Am J Surg. 2011; 201 (1):24-30. https://doi.org/10.1016/j.amjsurg.2010.07.039. 
33. James DRC, Orihuela-Espina F, Leff DR, Sodergren MH, Athanasiou T, Darzi AW, et al. The ergonomics of natural orifice translumenal endoscopic surgery (NOTES) navigation in terms of performance, stress, and cognitive behavior. Surgery. 2011;149(4):525-33. https://doi.org/10.1 016/j.surg.2010.11.019.

34. Jones Kl, Amawi F, Bhalla A, Peacock O, Williams JP, Lund JN. Assessing surgeon stress when operating using heart rate variability and the state trait anxiety inventory: will surgery be the death of us? Colorectal Dis. 2015;17(4): 335-41. https://doi.org/10.1111/codi.12844.

35. Wetzel CM, George A, Hanna GB, Athanasiou T, Black SA, Kneebone RL, et al. Stress management training for surgeons-a randomized, controlled, intervention study. Ann Surg. 2011;253(3):488-94. https://doi.org/10.1097/ SLA.0b013e318209a594.

36. Marteau TM, Bekker H. The development of a six-item short-form of the state scale of the Spielberger state-trait anxiety inventory (STAI). Br J Clin Psychol. 1992;31(Pt 3):301-6. https://doi.org/10.1111/j.2044-8260.1992. tb00997.x.

37. Miller R, Stalder T, Jarczok M, Almeida DM, Badrick E, Bartels M, et al. The CIRCORT database: reference ranges and seasonal changes in diurnal salivary cortisol derived from a meta-dataset comprised of 15 field studies. Psychoneuroendocrinology. 2016;73:16-23. https://doi.org/10.1016/j. psyneuen.2016.07.201.

38. Frison L, Pocock SJ. Repeated measures in clinical trials: analysis using mean summary statistics and its implications for design. Stat Med. 1992;11(13): 1685-704. https://doi.org/10.1002/sim.4780111304.

39. Erestam S, Bock D, Erichsen Andersson A, Bjartell A, Carlsson S, Stinesen Kollberg K, et al. Associations between intraoperative factors and surgeons' self-assessed operative satisfaction. Surg Endosc. 2019.

40. Kristenson MG, P.; Lundberg, U. The role of saliva cortisol measurement in health and disease. Oak Park: Bentham eBooks; 2012. https://doi.org/10.21 74/97816080534211120101.

41. Adam EK, Kumari M. Assessing salivary cortisol in large-scale, epidemiological research. Psychoneuroendocrinology. 2009;34(10):1423-36. https://doi.org/10.1016/j.psyneuen.2009.06.011.

42. Larsen CR, Soerensen JL, Grantcharov TP, Dalsgaard T, Schouenborg L, Ottosen C, et al. Effect of virtual reality training on laparoscopic surgery: randomised controlled trial. 2009:338:b1802.

43. Seymour NE, Gallagher AG, Roman SA, O'Brien MK, Bansal VK, Andersen DK, et al. Virtual reality training improves operating room performance: results of a randomized, double-blinded study. Ann Surg. 2002;236(4):458-63; discussion 463-454. https://doi.org/10.1097/00000658-200210000-00008.

44. Marrelli M, Gentile S, Palmieri F, Paduano F, Tatullo M. Correlation between surgeon's experience, surgery complexity and the alteration of stress related physiological parameters. PLoS ONE. 2014;9(11):e1 12444. https://doi.org/1 0.1371/journal.pone.0112444.

45. Taylor JA, Pandian R. A dissonant scale: stress recognition in the SAQ. BMC Res Notes. 2013;6(1):302. https://doi.org/10.1186/1756-0500-6-302.

\section{Publisher's Note}

Springer Nature remains neutral with regard to jurisdictional claims in published maps and institutional affiliations.

Ready to submit your research? Choose BMC and benefit from:

- fast, convenient online submission

- thorough peer review by experienced researchers in your field

- rapid publication on acceptance

- support for research data, including large and complex data types

- gold Open Access which fosters wider collaboration and increased citations

- maximum visibility for your research: over $100 \mathrm{M}$ website views per year

At BMC, research is always in progress.

Learn more biomedcentral.com/submissions 